\title{
SEED ECOLOGY OF SOME SELECTED DRY FOREST SPECIES OF SRI LANKA
}

\author{
K M G JAYASURIYA AND G A D PERERA \\ Faculty of Science, University of Peradeniya,
}

This study examines seed ecology of ten native dry zone forest species: Manilkara hexandra, Drypetes sepiaria, Salvadora persica, Bauhinia racemosa, Cassia fistula, Cassia siamea, Schlechera oleosa, Oroxylum indicum, Randia uliginosa, Dichrostachys cineria and in one alien invasive species: Prosopis juliflora.

Seed samples were collected from the dry zone of Sri Lanka (in Anuradhapura, Polonnaruwa, Monaragala and Hambanthota districts). Morphology (colour, width, length of seeds) and the weight of 60 seeds per each species were recorded in three replicates. Viability of seeds was tested using standard TTC test while the percentage germination of seeds was recorded in moist petridishes laid according to Randomize Complete Block Design. Rate of water absorption of seeds and seed coat widths were also measured, while the presence of water-soluble growth inhibitors were examined through a bioassay using Brasica juncea seeds. Hot water treatments, Hot air treatments, Gibberalic acid treatments, Manual scarification and combinations of above treatments were tested to break the seed dormancy of these species. Seed and plant characteristics were observed to determine the ecological state (Climax or Pioneer) of study species. Seed predation and dispersal mechanisms were observed during field visits.

P.juliflora and O.indicum seeds are recalcitrant, while the remaining species showed seed dormancy. D.cineria C.fistula, C. siamea and B.racemosa sceds appeared to be dormant due to its water impermeable seed coat and the dormancy can be overcome by manual-scarification. S.persica seeds contain underdeveloped embryo and hot water treatment (at $45^{\circ} \mathrm{C}$ for 5 days) was found to be the best treatment to break the seed dormancy. D.sepiaria, S.oleosa and R.uliginosa seeds seem to be dormant due to the presence of a growth inhibitor and the hard seed coat. Manual scarification together with Gibberalic acid (4000ppm) treatment was found to be suitable to break the seed dormancy of the species. M.hexandra seeds too have an undeveloped embryos and hard seed coats, which may cause seed dormancy, but seed germination can be improved by hot water treatment (at $85^{\circ} \mathrm{C}$ for 15 minutes) fallowed by manual scarification. O.indicum and R.uliginosa can be described as Pioneer species. Other 8 natural forest species can be described as climax species, which mainly dispersed by animals. High seed predation can be observed in these species. Especially insects including termites and several larvae of insects attack the seeds of these species.

Proceedings of the Ninth Annual Forestry and Environment Symposium 2003 of the Department of Forestry and Environmental Science. University of Sri Jayewardenepura, Sri Lanka 